\author{
Magdalena Markiewicz \\ ORCID: 0000-0002-6612-1505 \\ Uniwersytet Warmińsko-Mazurski w Olsztynie \\ m.markiewicz@uwm.edu.pl
}

\title{
Cluster - a new trend or necessity?
}

Date of submission: $5^{\text {th }}$ of January 2018; date of acceptance: $20^{\text {th }}$ of April 2018

JEL Classification: L20, L22, L26, L29, O10

Keywords: cluster, cooperation, economy, innovation

\section{Abstract}

Cluster - a new trend or necessity?

Enterprises from various industries are increasingly merging into cluster structures in which they see opportunities to develop their current activities and the opportunity to enter other markets. The theme of clusters is gaining increasing interest among business entities.

This study analyses the phenomenon of clusters, based on the observations of several existing clusters. This essay focuses mainly on an analysis of the essence of clusters. Since the study is based on literature research, the article is theoretical in nature.

The author assesses whether current cluster structures are just a temporary fashion, a new trend, or a real need of enterprises and concludes that clusters can provide economic benefits for regions and promote innovation.

\section{Introduction}

My experience with clusters began in 2012 when, as an entrepreneur, I tried to grow my company while attempting to establish a positive relationship with the competition. I felt the need for dialogue and cooperation in the local market. I realized that I could not strive for success alone, only cooperation within the group could ensure the success of my company. That is when I thought of the Japanese writer Ryunosuke Satoro, who wrote: Individually, we are one drop, together we are an ocean. I then noticed that the idea of a cluster carries huge potential.

Although the concept of clusters has been known in Poland for several years, and a number of cluster initiatives and clusters have already been created, know- 
ledge of networking is still very low. The word cluster is still a concept not understood by the majority of society, for others, it is only an over-interpretation of the word innovation. Therefore, everything that is innovative is fashionable. Clusters are also fashionable, which are undoubtedly innovative initiatives. But is this really just a blind rush for fashion, or something more?

My experience, resulting from several years of cooperation with entrepreneurs, university, and local governments, tends not to produce optimistic conclusions. The participants in many cluster initiatives and clusters still completely distrust each other and, in such a situation, good cooperation cannot exist. In my opinion, it will take a lot of time until the cluster concept is correctly understood in our country. We must change the mentality of Polish society, to talk about the strong cluster structures in our country. Only then will clusters be a motor of economic development. Despite several years of clustering interest in our country, the majority of cluster initiatives are still in an embryonic or vegetative state and do not contribute to the development of innovation in Poland. The state cluster policy (financing for the years 2007-2014) did not bring the expected results (strong cluster structures). Instead these powerful initiatives, poor caricatures of a network were created, which existed only to obtain start-up funds. After unsuccessful attempts to create a strong cooperation network, Polish cluster policy changed strategy and focused on financing only the key clusters. Such a solution is a good change for Polish clustering and will promote innovation in the regions.

I still believe that the cluster is a tool that enables the implementation of innovation in practice and is a way to increase regional competitiveness, as described by D. Doncheva (2016, p. 279). I believe that clustering is today a necessity, not just an economic fad.

\section{The essence of the cluster}

\section{By Porter's definition,}

clusters are geographic concentrations of interconnected companies, specialised suppliers, service providers, firms in related industries and associated institutions, in particular fields that compete but also cooperate. Critical masses of unusual competitive success in particular business areas, clusters are a striking feature of virtually every national, regional, state, and even metropolitan economy, especially those of more economically-advanced nations. (Porter 2001, p. 246)

There are a number of cluster definitions in the literature. According to one view: a cluster is deliberately created as a network of entities operating in territorial proximity $\left(\mathrm{PARP}^{1}\right.$ ). Lilia Knop (Knop 2013, p. 33) has a similar view of the term cluster. According to her, a cluster is a group of entities from various backgrounds: business, science, local government, and civil society, consciously

${ }^{1}$ PARP — Polska Agencja Rozwoju Przedsiębiorczości (Polish Agency for Enterprise Development). 
operating in a specific ecosystem, focused on a specific territory and/or around a set of specialisations. Through my experience with the topic of clusters for several years, I have created my own cluster definition:

A cluster is a group of collectively cooperating entities/participants: enterprises, research institutions, administrative units, and business environment institutions, which are focused on common ideas and goals, generating new added value and synergies which increases productivity and brings other additional economic benefits.

A significant element between entities in the cluster is coopetition (competition and cooperation) - a situation that occurs when the network develops cooperation in which participants work together to achieve common benefits without ceasing to be competitors. Competition does not exclude mutual beneficial interaction with other companies and may become an engine for their development; these cooperative actions may also produce synergetic relationships in the cluster.

Other distinguishing features of clusters:

- The geographical proximity of cluster members, so that it can occur the positive effects of information diffusion and use the same resources;

- The common trajectory of development - business activity must be directed to a common goal;

- Relationship - interactions between businesses are very important.

Following the article by Doncheva, we can define different types of clusters, based on various criteria:

- number of companies and industries that form the cluster;

- type and level of integration;

- geographical scope and configuration;

- administration of common action;

- product specialisation;

- technological specialisation.

It should be noted that clusters are present in almost all sectors of the economy, including in industry and services. They are characterized by different levels of innovation as well as by different development perspectives and strategies. Entities forming clusters may include: entrepreneurs, government, universities, institutes, research centres, business institutions and non-governmental organisations (NGOs).

The cooperation between all of the above entities increases the efficiency and competitiveness of enterprises. This is a synergetic relationship, using the strengths of each of the entities to achieve measurable results.

Areas of cooperation of the business enterprises with research units in the cluster may include different elements, such as: implementation of joint research projects and personnel training for the cluster members. Such cooperation brings mutual benefits. The science sector gives businesses useful knowledge and access to expert support and the scientific community has an opportunity to verify their research in practice. This cooperation may have practical value when it becomes, 
for example, an instrument for expanding the educational offer. Both business entities and representatives of science emphasize the importance of mutual cooperation. The following are the areas in which science can support business:

— new technological solutions;

- innovations;

— common research projects;

- market analyses based on data available to universities.

The competences of those concerned and the need for agreement are very important factors in such cooperation. The most important element in the idea of clusters is that they become fertile ground for innovation and increase the competitiveness between companies, and benefit the global economy. For this reason, the concept of clusters is becoming increasingly popular in both Europe and Poland.

\section{Analysis of the role and importance of the clusters}

In order to analyse the role and importance of clusters, the benefits for both the regional economy and other entities should be considered. Creating new clusters, and developing existing clusters in a region is associated with a series of phenomena that improve competitiveness and innovation in the area, such as:

- shaping the market of specialised production factors;

- creating new entities in a region;

- creating an attractive labour market;

- stimulating the flow of knowledge;

- the development of scientific infrastructure in the region;

— increasing the attractiveness of the location for foreign direct investment (FDI).

Items that play a key role from the point of view of an individual enterprises:

- reduce operating costs;

— facilitating the diffusion of innovation;

- capabilities for creation of new businesses;

- growth in labour productivity;

- facilitating the process of brand building;

— better access to employees and suppliers;

- access to specialised information;

Besides benefits, there are some negatives to the cluster participants as well:

- dependence of other participants;

- the risk of forming cartels;

— conflict of interest (Simmie 2004, pp. 1099-1103).

The functioning of clusters also provides advantages and disadvantages for the region. Here are some examples. Clearly, the advantages of clusters include 
a higher level of innovation in the region and higher productivity. Clusters also contribute to the growing number of new companies and, thus, new jobs. This contributes to increased competition in the market and stimulates it positively. An example of such a cluster is the Silesian aviation cluster which, as part of the Innovative Economy Operational Programme, has launched, among others, a modelling house, in which cluster members work on new aerodynamic models. As part of this activity, an investment was made in 3D printing and scanning technology. This allowed a competitive advantage to be gained (www1). Another example of a cluster that introduces innovativeness in a region and higher productivity is Aviation Valley, which, as part of the HiPAir project, has developed innovative concepts and tools to increase the competitiveness of aviation companies based on more effective human resource management and the use of their employees' competences and skills (www2).

Are there any disadvantages of clustering? One of the drawbacks of clustering is certainly overly-narrow specialisation. Clusters tend to focus on a selected industry, which produces growth only in that sector. Clusters can also cause technological isomorphism, i.e., the creation of schematic technological innovation by various companies, thus slowing the creation of new ideas. Clusters may cause increasing labour and real estate costs. As we see, there are several advantages, but also disadvantages in the functioning of clusters. Clusters are, therefore, not a panacea to regional economic problems, because they can also cause adverse effects (Holton 2000).

I think that clusters, despite their flaws, are the future of the modern economy. The best example of the success of a cluster and the development of a region, is the most famous cluster in the world: Silicon Valley. This cluster encompasses more than 6,000 companies. The first company invested there in 1912 (www4). Currently, the activities of Silicon Valley are associated with the operation of giant electronics and ICT companies. The example of Silicon Valley shows that innovative clusters drive the development of the world. Clusters throughout the world differ in their structure and management, so there is no single ideal model of a cluster. Vividly illustrated by W. Conrad Holton (2000, p. 77-80) in his article about clustering in the states it showed that,

each region evolves its cluster in a different way. Some can afford a paid staff, some create a common exhibit for fairs, some work very closely with local governments and others just continue an unofficial network. (Holton 2000, pp. 77-80)

In Poland, the phenomenon of clustering is not yet fully mature. Most of the currently operating clusters are rather 'germs' than mature structures. In Poland, there are also clusters which are of international significance. An example is Aviation Valley, which is an important European centre for the aerospace industry. Aviation Valley is the pride of the Podkarpacie Voivodeship. Several years ago, hardly anyone would have thought that components for Airbuses and F16s would 
be created in this corner of Europe. However, there are other clusters like Aviation Valley in Poland. These small clusters are still in the embryonic phase. With the inventory of clusters by the Polish Agency for Enterprise Development in 2015, it was found that in Poland, there are 134 clusters which developed in the years 2003-2015. Most of them (over 60\%) are young clusters and 106 potential cluster initiatives have also been identified (www3).The clusters in Poland are young structures, compared to clusters in Europe and in the world. According to the results of benchmarking, conducted in Europe within the framework of the project NGP Excellence, clusters were created mainly in the years 1997-2010 (in Finland between 1997 and 2007, in Germany in 1998-2006, in Austria - 1999-2003, in Denmark - 2003-2010, in Norway - 2003-2007, in Sweden after 2004, in France after 2005, and in Spain after 2006) (Lämmer-Gamp et al. 2012).

In recent years, interest in the subject of clusters in Poland has been gradually increasing. Entrepreneurs have begun to see the possibility of achieving significant benefits from participation in these structures. Clusters have become an increasingly appreciated factor in the development of innovation and competitiveness (Oinas \& Malecki 2002, pp. 363-372). Due to its nature, they promote close cooperation between business and science. However, it should be noted that no organisation can innovate by itself. Here again I quote Ryunosuke Satoro; "Individually, we are one drop. Together, we are an ocean". ${ }^{2}$ Firms have established different forms of cooperation with a number of external partners, all in an effort to develop new technologies, products, and services. As clusters develop, they gradually increase their reach, attract people, technologies, investments, and seek other clusters to provide complementary products or establish cooperation. We should be aware, however, that functioning clusters may also be associated with potential negative effects for the region, such as the danger that clusters can be transformed under certain conditions into cartels, rigging higher prices for customers, damaging the natural environment, or contributing to the creation of a monopoly in a region.

Both in Poland and abroad, there are projects for the political support for clusters. The concept of stimulating competitiveness and economic growth, through the development of clusters (Cluster-based policy) should be a well-planned regional policy, promoting the formation of such structures. Cluster support at the regional level should be implemented by promoting a bottom-up approach to the development of clusters, which means that the main participants involved in the process of building a cluster initiative should be enterprises. The activity of public authorities in the clustering process should focus primarily on the creation of appropriate institutional infrastructure in the cluster environment and providing various assistance programmes. In the future, they should move away from supporting cluster initiatives which would not be able to develop without support

2 Ryunosuke Satoro, known maxim, aphorism. 
from the government. A good prospect for Polish regional development are key clusters. Figure 1 shows such a relationship. In the future, key clusters which stand out and are globally competitive will be the most generously subsidised.

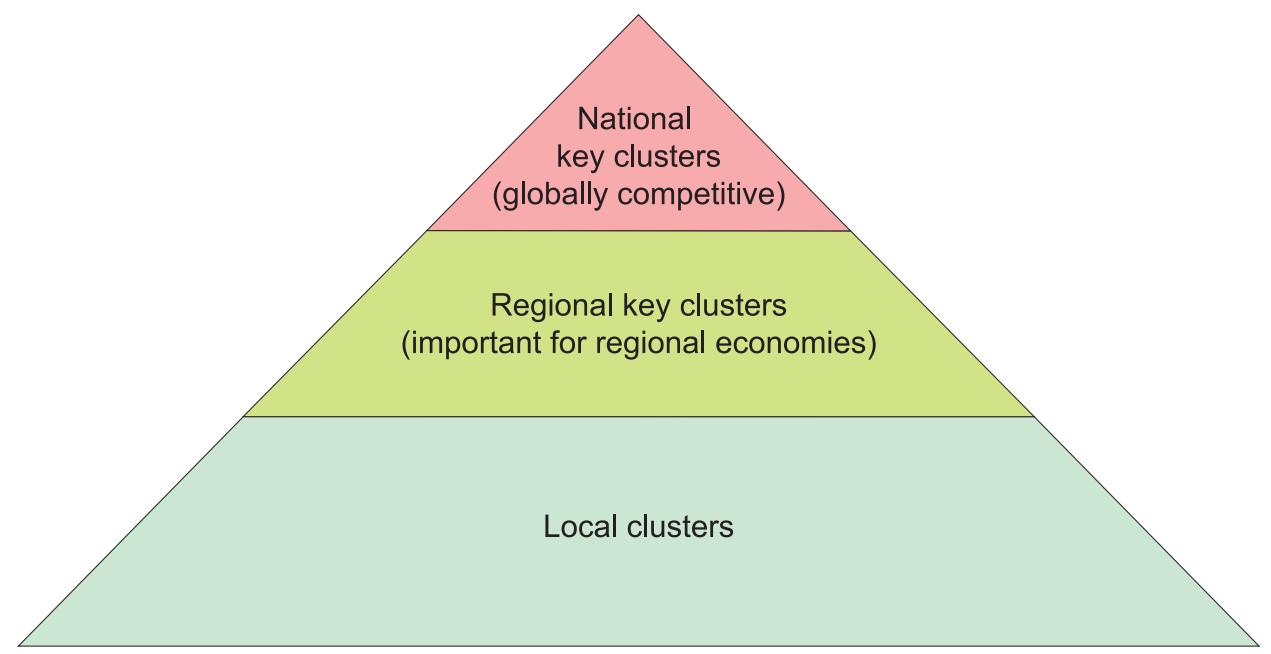

Figure 1. Map of clusters in Poland (2020)

Source: Author.

The new financial perspective for the years 2014-2020 supports smart specialisation. Smart specialisation is based on three complementary elements: science, education, and the regional economy. By changing the financial policy, funds for research and development will be spent more effectively and will benefit the individual regions.

Referring to this point to Michael Porter, he provides a few hypotheses why clustering delivers innovation. According to him, these are:

- Rapid perception of new buyer needs;

- Concentrates knowledge and information;

— Facilitates relationships with other institutions;

- Rapid assimilation of new technological possibilities;

— Provides richer insights into new management practices.

\section{Conclusion}

Clustering currently is not only an opportunity, but also a need and an economic necessity. Regional competitiveness is not determined by the activities of a single company, but by the group. This synergic potential, therefore, allows entities operating in clusters to achieve far greater benefits. The presence of clusters in the Polish regional economy shows not only the level of its development, but also points 
to the potential of Polish regions and their further development prospects. Clusters have become a permanent and essential part of all developed and developing economies. At the regional level, clusters contribute to the economic development of the community - they stimulate the regional economy by providing essential goods and services and they foster the development of regional enterprises and local development - e.g., by improving infrastructure. Considering these examples of the benefits of cooperation within the clusters, we can conclude that a cluster is a form of cooperation which positively affects the development of entrepreneurship in the region. Above all, it should be emphasised that this kind of cooperation significantly increases the number of emerging innovative solutions, which are a key element in the development of entrepreneurship. It must also be noted that in order to achieve the positive effects of clustering, proper conditions for its development must be created.

The idea of clustering in Poland is relatively new and still developing. It should be noted that every year there are noticeable positive changes forming a solid basis for the development of clustering in Poland in the near future. For this to happen, all participants in cluster initiatives (entrepreneurs, government, scientific units) must do more extensive work on the development of their cooperation. It is through this work, as shown by foreign examples, that clusters can be the strength of the region as well as provide the basis for the dynamic development of entrepreneurship. I believe in clusters and the meaning of their development in Poland. I think clusters are the key to innovation as well as a test of maturity and the ability to cooperate.

\section{References}

Doncheva D. (2016), "Cluster - way for increasing the competitiveness of regions", Trakia Journal of Sciences, Vol. 14, no 3, pp. 275-279.

Holton W.C. (2000), Think Globally, Cluster Locally, „Marketwatch” Vol. 36, no 1, pp. 77-80.

Knop L. (2013), Zarzadzanie klastrem. Koncepcje, strategie, modele, Gliwice.

Lämmer-Gamp T., Meier zu Köcker G., Christensen T., \& Muller L. (2012), Clusters are Individuals. New Findings from the European Cluster Management and Cluster Programme Benchmarking, Vol. 2, The Danish Ministry of Science, Innovation and Higher Education, Copenhagen.

Oinas P., \& Malecki E.J. (2002), "The evolution of technologies in time and space: From national and regional to spatial innovation systems", International Science Review, Vol. 25, no 1, pp. 102-131.

Porter M.E. (2001), Porter o konkurencji, Warszawa.

Simmie J. (2004), "Innovation and clustering in the globalised international economy", The Editors of Urban Studies, Vol. 41, no 5/6, pp. 1095-1106. 


\section{Internet sources}

www1: www.aerosilesia.eu (access: 15.11.2017).

www2: www.dolinalotnicza.pl (access: 15.11.2017).

www3: www.pi.gov.pl (access: 20.11.2017).

www4: www.siliconvalley.com (access: 25.11.2017). 